\title{
Effectiveness of interventions in patients with speech disorders. A meta-analysis of experimental studies
}

\author{
Camelia Daniela Cucu',2, Florinda Golu', Andreea Raluca Adam¹ \\ ${ }^{1}$ Faculty of Psychology and Educational Sciences, University of Bucharest, Romania \\ ${ }^{2}$ Neurology Department, Colentina Clinical Hospital, Bucharest, Romania
}

\begin{abstract}
Objectives. The study aims to conduct a meta-analysis on the existence of solid experimental evidence to highlight the effectiveness of interventions in the improvement of speech disorders in patients who have suffered a stroke. It is desired to identify those moderating variables that can influence the effectiveness of these interventions over time, or that demonstrate the extent to which chronicity of stroke may lead to inferior results in speech improvement. Materials and methods. A search was conducted in three databases: Cochrane Library, Web of Science and PubMed, to identify those studies that meet the criterion for intervention, starting with the first records and until now. The qualitative analysis of the studies was performed using Risk of Bias, and the quantitative analysis through Comprehensive Meta-Analysis.

Results. As a result of selection, 31 randomized clinical studies were included in the current research, out of the 1923 existing studies. These have been the subject of investigation on aphasia and dysphagia, with a wide range of types and methods of intervention. The results show that the difference in averages between the intervention group and the post-test control group is a significant one $(g=0.528 ; 95 \% \mathrm{Cl} 0.067 ; 0.004 ; p=0.000)$, while the moderation analysis did not record a statistical significance.

Conclusions. Non-pharmacological interventions based on the recovery of speech disorders as a result of stroke have been shown to be effective in many of the researches in specialized literature. Their results show that, as a result of therapies, patients experience improvements in quality of life, communication and many psychiatric disorders. However, it is not clear how effective these interventions are in recovering or ameliorating speech disorders.
\end{abstract}

Keywords: aphasia, dysphagia, stroke interventions, speech disorders, meta-analysis

\section{INTRODUCTION}

In addition to the medical act itself, post-stroke recovery is achieved following a diagnosis and evaluation process that refers to: identifying the patient's needs, setting clear, realistic and achievable intervention goals, the actual intervention to achieve the objectives as well as evaluating and recording the patient's progress. Rehabilitation techniques are based on the neurophysiological principles of motor control and recovery by: applying electrical stimuli to facilitate or inhibit an activity [1]; use of motor re-learning methods; as well as general relationship and communication techniques.
Although some systematic researches reveals that no treatment with a higher effectiveness than another [2] has been identified, needed to investigate treatments so that they can be objectively evaluated, on clear criteria, to use the benefits of these therapies. Research with positive results in patient symptoms brings strong arguments for multidisciplinary interventions, but with certain limitations in terms of the application of interventions using technology, without additional support from qualified staff in medical and speech therapy recovery. Subsequent stroke, dysphagia affects more than $50 \%$ of patients with a very high risk of death due to swallowing deficiencies of about $30 \%$ 
of all cases. The treatment of dysphagia includes both compensatory and rehabilitative approaches.

Meta-analytical studies made to this date, referring to recovery therapies for speech disorders, although there is a limited amount of research on these therapies, show that interventions based on neuromuscular electrical stimulation appear to be more effective than those based on mechanical stimulation. Two other meta -analysis argue that more evidence is needed to show that these interventions are effective over time and especially more protocols and measurements of speech disorders are needed, so that the variability of the results of interventions would be reduced [3].

Although interventions on speech disorders have been researched at a meta-analytical level, the present study makes a substantial contribution in this area, by selecting controlled and randomized studies, by narrowing the causes of speech disorders and exclusively selecting those that are secondary to stroke and especially by the fact that variables such as the chronicity of stroke and the sustainability of interventions over time have been taken into account.

\section{MATERIALS AND METHODS}

\section{Search strategy}

The studies were collected from the electronic databases Web of Science, PubMed and Cochrane Library, starting with the first registrations until February 2021. A search strategy was developed for each database, using a combination of free text and keywords in the title and abstract of the studies. The search was limited to studies published in English, in the medical and psychological aria.

\section{Selection criteria}

The selected studies were chosen in two stages: (a) examination of titles and abstracts to identify those keywords and criteria relevant to the present research; and (b) examination of articles in extenso using the eligibility criteria recommended in systematic reviews and meta-analysis.

Only studies that met the following conditions were included: they had a randomized experimental design (RCT); they have clearly delimited the target population from other types of population; they reported the result obtained on patients after the intervention; instruments of objective measurement of the results of the intervention to have been applied to the participants in the study; existence of a control group; speech disorder to be secondary to stroke; age of patients over 18 years; minimum number of 4 participants in each group.

\section{Exclusion criteria}

Following the examination of the items selected in the first stage of the present study, 111 ineligible items were excluded applying the following exclusion criteria, different from the previous ones, as follows: the studies reported results other than expected (e.g.: psychosocial manifestations, psychiatric disorders); other procedures than the medical or speech and language recovery ones were applied (e.g. alternative treatments); reporting different specific indicators from those used in the present study; studies that introduced into the intervention participants suffering from different types of conditions other than stroke.

\section{Risk of bias assessment}

The qualitative evaluation of the included studies was performed using Risk of Bias, a tool applied through the RavMan V 5.3 software, developed by the Cochrane Collaboration. The qualitative evaluation takes into account seven criteria, as important sources of error in controlled experimental studies: adequate generation of the allocation sequence; knowledge of the allocation to one of the conditions; allocation information for participants and facilitators; ignorance of the evaluated results; incomplete results; selective reporting; other errors - these may be due to the small sample size, diversity of participants or interventions or other quality measures.

\section{Moderating variables}

In this study, two variables were selected as moderators to see if they can influence the results of interventions on patients with speech disorder. First, the severity of the speech disorder, an acute or chronic categorical variable, was used. The acute phase refers to the first three months poststroke [3], the most important period for recovery and especially to obtain the most important improvements following therapeutic interventions. The chronic phase refers to those studies in which 
patients received intervention more than 3 months after the stroke. The second categorical moderator refers to the post-intervention evaluation period. The evaluation intervals furthest from the end of the intervention were selected. The differentiation criterion was selected for an evaluation interval less than six weeks, respectively more than six weeks, from the end of the intervention.

\section{Meta-analytical procedures}

For each study [4-33], the relevant data regarding the present research were collected, referring to: the identification reference of the study; patient characteristics (number of patients in each group, age, type of speech disorder, type of stroke); details of the intervention (type, stages and duration of the intervention); the results evaluation tool; the area under research; the time of the last evaluation.

For the quantitative processing of the results, the indicators of the average and standard deviation were extracted, both for the experimental and control group, as well as the number of participants to each of the conditions. The data were processed using the Comprehensive Meta-Analysis (CMA) V3 software.

The meta-analysis was performed through some stages. The average between the intervention and control group was compared for each study and the difference of the average between the two groups was reported within the post-test. The size of the effect was calculated considering the average, standard deviation and number of participants within the post-test, with a control group. Differences in the standard average were reported using fixed and random effect models, with an estimate point of $95 \%$, a confidence interval, with a statistical significance level of 0.05 . The heterogeneity of the studies was tested using the $\mathrm{I}^{2}$ test. A score of $\mathrm{I}^{2}>50 \%$ indicates a significant heterogeneity. A meta-regression analysis was performed for the two moderating variables: the stroke type - acute or chronic - and the evaluation period $<6$ weeks, compared to $>6$ weeks.

\section{RESULTS}

\section{Analysis of the included studies}

1,923 studies were found in databases. After excluding ineligible items, 31 studies were included in the qualitative and quantitative analysis (Figure 1).

\section{Risk of bias qualitative assessment of the includ- ed studies}

Overall, the qualitative analysis of the risk of error of the studies is optimal (Figure 2). Out of the

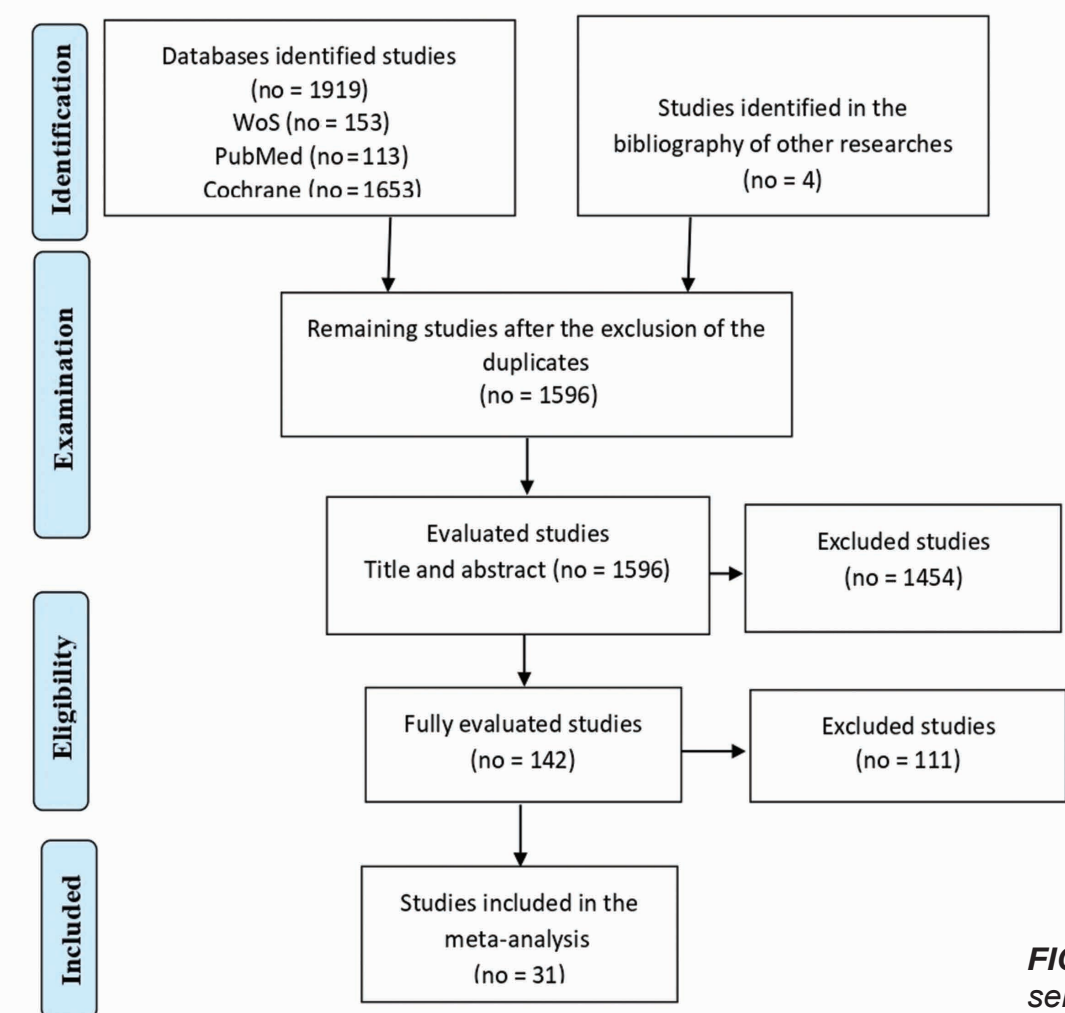

FIGURE 1. Diagram of the study selection process 


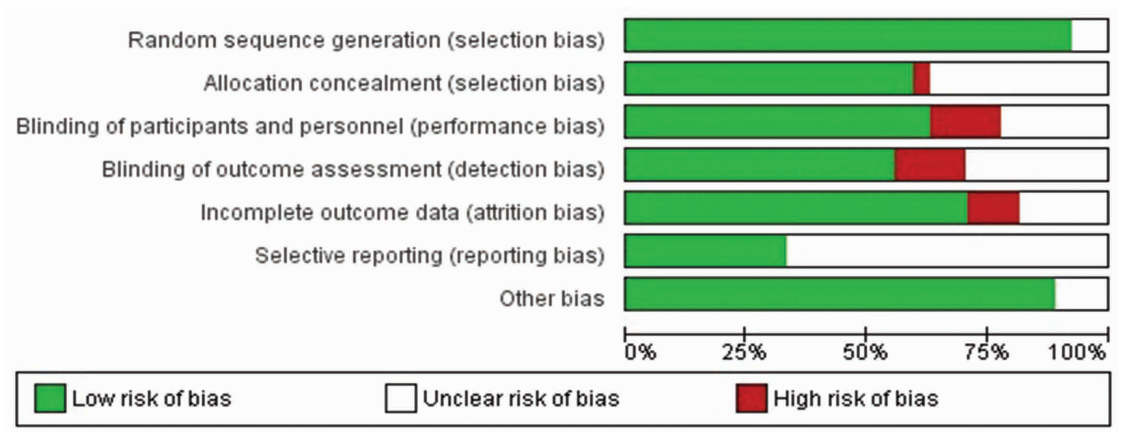

FIGURE 2. The percentage risk of bias assessment for the included studies

31 analysed studies, nine met one high risk criterion and out of the seven used by the selected instrument, one study met two high risk error criteria.

The highest risk of error is the detection error which is represented by the evaluator's criterion of knowing the allocation of participants in each group (Figure 3).

\section{Quantitative analysis of studies}

The main results show the standardized effects of the differences between averages (Figure 4) in interventions on patients with post-stroke speech disorders. The average of the size of the effect representing the efficacy of speech disorder recovery interventions on stroke patients is $\mathrm{g}=0.0542(95 \%$ CI $0.0442 ; 0.0642 ; \mathrm{p}=0.000)$, in the fixed-effect model and $\mathrm{g}=0.528$ (95\% CI $0.067 ; .004 ; \mathrm{p}=$ 0.000 ), in the random model, for all 31 studies, respectively 37 results.

The heterogeneity was moderate $\left(\mathrm{I}^{2}=31,252\right)$ (Table 1), which means that approximately $31 \%$ of the variance of the observed effects reflects the actual variance, the rest being sampling error. The results show that the effectiveness of interventions is significant.

The Funnel Plots graphic (Figure 5) reveals the symmetry of the effects of the interventions and indicates that they are symmetrical enough, while the trim-and-fill analysis suggests the adjustment to the average sizes of the effect.

To observe the effect of the intervention, depending on each speech disorder controlled within the study, the statistical analysis reveals that, for aphasia $(\mathrm{N}=18, \mathrm{~g}=0.528,95 \% \mathrm{CI}=0.393 ; 0.664$, $\left.\mathrm{I}^{2}=6.179 ; \mathrm{p}<0.000\right)$, the effect is significant. For dysphagia $(\mathrm{N}=19, \mathrm{~g}=0.559,95 \% \mathrm{CI}=0.076$; $\left.0.006, \mathrm{I}^{2}=47.306 ; \mathrm{p}<0.000\right)$, the effect is also significant (Figure 6). The results highlight the fact the intervention programs improve the health of post-stroke patients, in terms of aphasic and dysphasic disorders.

\section{Moderation analysis}

The meta-regression analysis of the stroke type at the time of the intervention did not reveal statistically significant differences between the acute

TABLE 1. Statistical results between the control group and intervention group

\begin{tabular}{|l|l|l|l|l|l|l|l|l|l|}
\hline Model & Result & $\mathrm{N}$-comp & $\mathrm{H}-\mathrm{g}(95 \% \mathrm{Cl})$ & Std. Er. & Variance & $\mathrm{LL}$ & $\mathrm{UL}$ & $\mathrm{Z}$ & $\mathrm{I}^{2}$ \\
\hline Fixed & All interventions & 37 & .542 & .051 & .003 & .442 & .642 & $10.594^{* *}$ & 31.252 \\
\hline Random & All interventions & 37 & .528 & .067 & .004 & .397 & .658 & $7.922^{* *}$ & \\
\hline Fixed & Aphasia & 18 & .528 & .069 & .005 & .393 & .664 & $7.648^{* *}$ & 6.179 \\
\hline Random & Aphasia & 18 & .506 & .075 & .006 & .359 & .653 & $6.746^{* *}$ & \\
\hline Fixed & Dysphagia & 19 & .559 & .076 & .006 & .409 & .708 & $7.336^{* *}$ & 47.306 \\
\hline Random & Dysphagia & 19 & .592 & .110 & .012 & .377 & .807 & $5.391^{* *}$ & \\
\hline${ }^{*} p<0.05, * * p 0.01$ & & & & & & & &
\end{tabular}

TABLE 2. Statistics of meta-regression model

\begin{tabular}{|l|c|c|c|c|c|c|c|c|c|}
\hline & Coefficient & $\begin{array}{c}\text { Std. } \\
\text { Error }\end{array}$ & LL & UL & Z-value & Tau $^{\mathbf{2}}$ & $\mathbf{I}^{\mathbf{2}}$ & $\mathbf{Q}$ & $\mathbf{R}^{\mathbf{2}}$ \\
\hline $\begin{array}{l}\text { Type of } \\
\text { stroke }\end{array}$ & .823 & .617 & -.387 & 2.034 & 1.33 & 1.963 & 75.1 & 136.57 & .240 \\
\hline Duration & .59 & .555 & -.498 & 1.68 & 1.06 & .982 & 74.49 & 1.13 & .158 \\
\hline
\end{tabular}




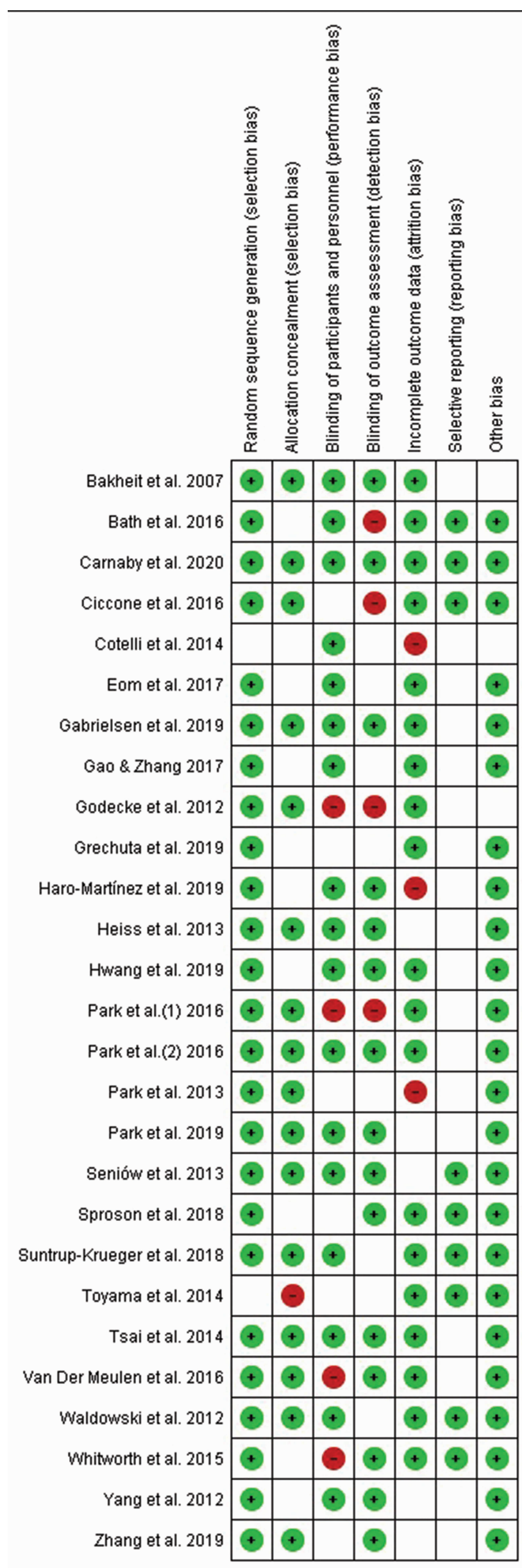

FIGURE 3. Summary of risk of bias, by components, for each included study and the chronic type $(\mathrm{N}=35, \mathrm{~g}=0.823,95 \%$ $\left.C I=-0.387 ; 2,034, I^{2}=75.1 ; p>0.05\right)$. Also, the follow-up period is not a statistically significant moderator $(\mathrm{N}=37, \mathrm{~g}=0.59,95 \% \mathrm{CI}=-0.498$; $\left.1.68, \mathrm{I}^{2}=74.49 ; \mathrm{p}<0.05\right)$, the data being shown in Table 2. Thus, the effectiveness of the interventions does not appear to be influenced by the time that has passed since the occurrence of stroke and the moment when the intervention to treat and improve the speech disorders was initiated.

\section{DISCUSSION}

The purpose of this study was to examine the effectiveness of interventions on recovery and improvement of speech disorders in patients who have suffered a stroke, through controlled studies in the specialized literature. This meta-analysis includes studies of interventions, both with the help of speech therapy and speech tools (facilitated by a speech therapy recovery specialist or by certain self-treatment programs), and with the help of medical tools and equipment (electrical neuromuscular stimulation, electrical pharyngeal stimulation, inhibitory repetitive transcranial magnetic stimulation, etc.). All the selected studies had batteries of medical and psycho-linguistic tests as instruments for measuring the symptomatology, standardized and adapted to the reference population. The effects of the intervention over time were examined in post-stroke patients, as well as the investigation of two specific moderators: one from the medical perspective - the type of stroke, and the other from the perspective of sustainability of the results of the interventions.

Of the 1,923 studies, 31 were selected, with a total number of 1,430 participants, of which 792 in the intervention group and 638 in the control group. The results measured in patients with poststroke speech disorders regard speech recovery, improved quality of life related to communication, speech function, argument structure of sentences, but also dysphagia and increased capacity and safety of swallowing.

The general objective of this meta-analysis was to identify whether, following therapies focused on speech recovery, the interventions are sustainable, so that a research based on multidisciplinary intervention in the recovery of patients with speech disorders could be initiated. The first objective of 
Statistics for each atudi

\begin{tabular}{|c|c|c|c|c|c|c|}
\hline $\begin{array}{l}\text { 9dges's } \\
g\end{array}$ & $\begin{array}{l}\text { Standard } \\
\text { error }\end{array}$ & Varlance & $\begin{array}{l}\text { Lower } \\
\text { limit }\end{array}$ & $\begin{array}{l}\text { Upper } \\
\text { llimit }\end{array}$ & Z-Value & p-Valu \\
\hline 0.159 & 0.345 & 0.119 & -0.516 & 0.835 & 0.062 & 0.64 \\
\hline 0.092 & 0.350 & 0.116 & .0 .574 & 0.758 & 0.271 & 0798 \\
\hline 0.136 & 0.182 & 0.033 & .0 .218 & 0.494 & 0.762 & \\
\hline 0.057 & 0.350 & 0.116 & .0 .009 & 0.724 & 0.169 & 0.80 \\
\hline 0.019 & 0.345 & 0.119 & .0 .656 & 0.695 & 0.057 & 0.955 \\
\hline 0.002 & 0.004 & 0.365 & -0.781 & 1.596 & 0.668 & 0.505 \\
\hline 0.930 & 0.501 & 0.251 & -0.051 & 1.911 & 1.859 & 0.063 \\
\hline 0.924 & 0.401 & 0.161 & 0.139 & 1.710 & 2306 & \\
\hline 0.964 & 0.503 & 0.162 & 0.175 & 1.753 & 2394 & \\
\hline 0.731 & 0.115 & 0.013 & 0.506 & 0.957 & 6.364 & 0.000 \\
\hline 0.7003 & 0.263 & 0.069 & 0.186 & 1.218 & 2.674 & 0.007 \\
\hline 0.701 & 0.263 & 0.069 & 0.186 & 1.216 & 2.696 & .00 \\
\hline 0.197 & 0.258 & 0.067 & 0.310 & 0.7003 & 0.761 & 0.44 \\
\hline 0.735 & 0.478 & 0.229 & -0.2002 & 1.672 & 1.537 & .12 \\
\hline 0.399 & 0.433 & 0.187 & -0.450 & 1.247 & 0.921 & 357 \\
\hline 1.222 & 195 & 0.156 & 0.447 & 1.996 & 3091 & \\
\hline 0.359 & 0.423 & 0.179 & -0.470 & 1.189 & 0.849 & 300 \\
\hline 0.350 & 0.537 & 0.289 & -0.723 & 1.392 & 0.614 & \\
\hline 0.291 & 0.301 & 0.091 & -0.299 & 0.891 & 0.968 & \\
\hline 0.643 & 0.496 & 0.236 & -0.310 & 1.596 & 1.323 & 16 \\
\hline 0.000 & 0.290 & 0.084 & .0 .569 & 0.509 & 0.000 & \\
\hline 0.356 & 0.324 & 0.105 & .0 .279 & 0.992 & 1.099 & \\
\hline 0.721 & 0.396 & 0.149 & .0 .036 & 1.478 & 1.067 & $\alpha$ \\
\hline 1.070 & 0.298 & 0.009 & 0.496 & 1.655 & 3.568 & 0.0 \\
\hline 0.363 & 0.453 & 0.205 & -0.525 & 1.251 & 0.802 & 0.4 \\
\hline 0.712 & 0.328 & 0.108 & 0.009 & 1.355 & 2.171 & 0.0 \\
\hline 0.696 & 0.327 & 0.107 & 0.044 & 1.327 & 2096 & 0.0 \\
\hline 0.410 & 0.221 & 0.103 & -0.219 & 1.039 & 1.277 & 02 \\
\hline 0.353 & 97 & 158 & -0.445 & 1.111 & 0.838 & \\
\hline 1.696 & 0.300 & 0.090 & 1.097 & 2274 & 5.616 & 0.00 \\
\hline 0.479 & 0.387 & 0.150 & .0279 & 1.237 & 1.239 & 0.21 \\
\hline 0.478 & 0.272 & 0.074 & -0.054 & 1.010 & 1.760 & 0.07 \\
\hline 0.265 & 0.470 & 0.221 & .0 .656 & 1. 186 & 0.564 & \\
\hline 0.015 & 0.300 & 0.144 & .0 .730 & 0.759 & 0.039 & 0.9 \\
\hline 0.294 & 0.509 & 0.259 & .07003 & 1.291 & 0.578 & \\
\hline 1.442 & 0.574 & 0.350 & 0.316 & 2567 & 2510 & \\
\hline 0.644 & 0.318 & 0.101 & 0.021 & 1.268 & 2025 & \\
\hline 0.542 & 0.051 & 0.003 & 0.442 & 0.642 & 10.594 & \\
\hline
\end{tabular}

FIGURE 4. Statistics of the included studies
Hedger's g and $95 \% \mathrm{Cl}$
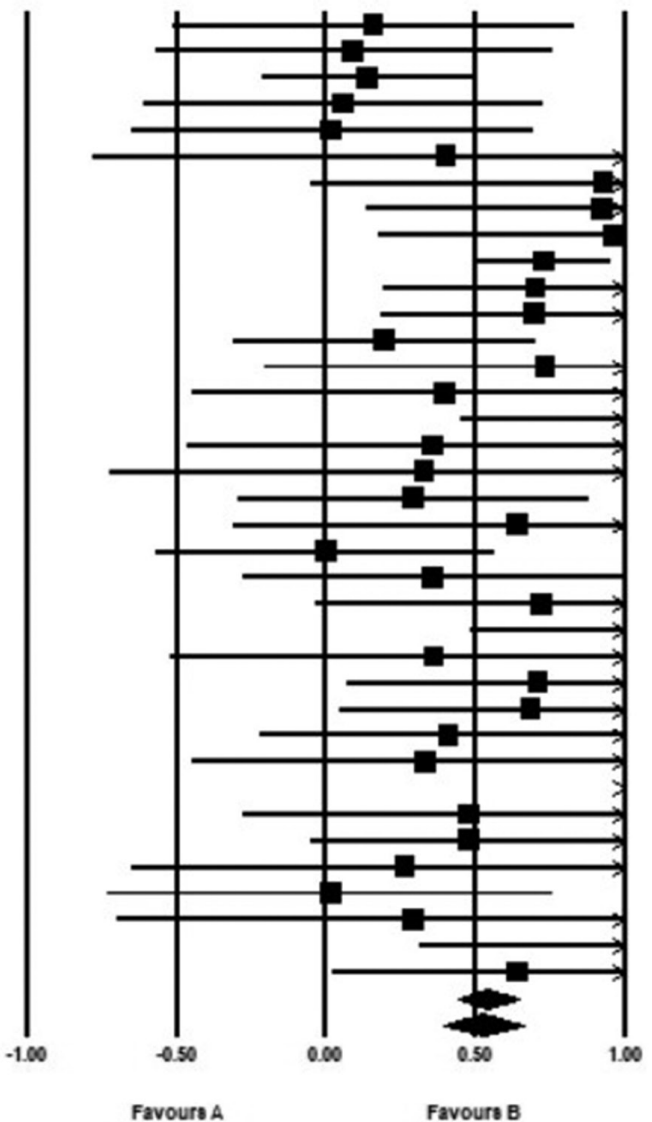

Funnel Plot of Standard Error by Hedges's g

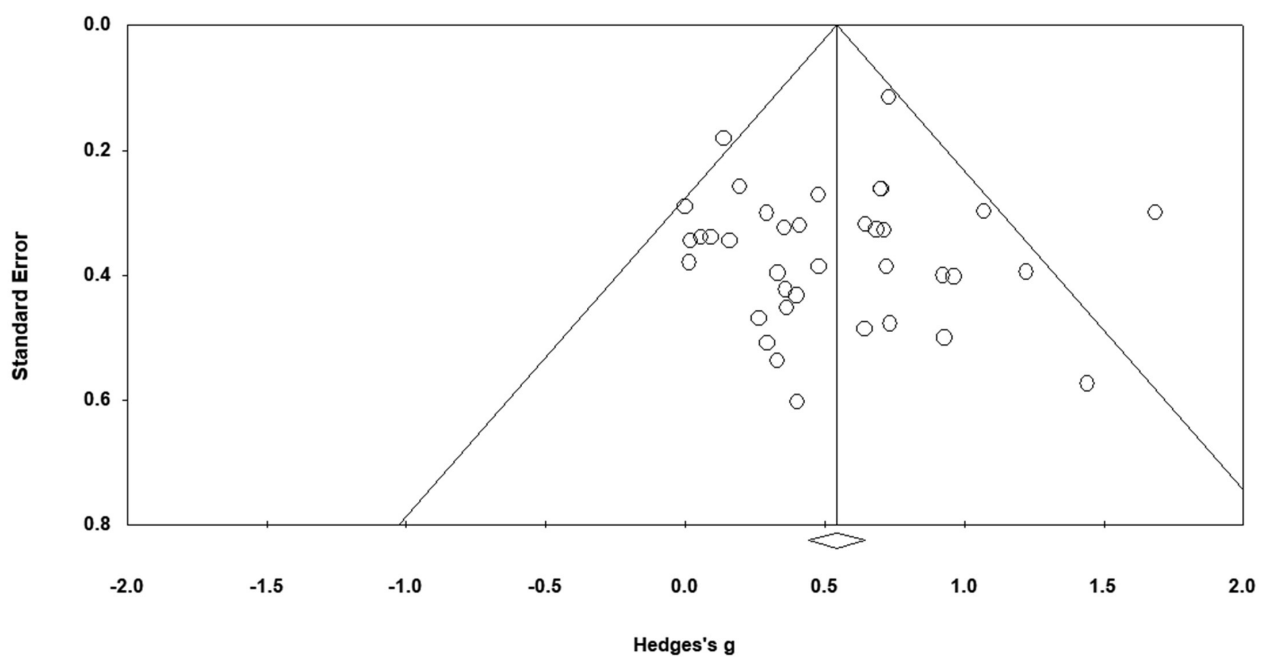

FIGURE 5. Standard error graphic of the results

the paper is to observe a statistically significant effect of the interventions that focus on the recovery of speech disorders in stroke patients. The results showed that these interventions are generally effective and that, in both aphasia and dysphagia, medical and educational interventions can bring significant long-term benefits to these patients. These results are in line with other studies showing the effectiveness of interventions in speech disorders. At a psychological level, such an intervention can increase the quality of life and interpersonal relationships at a communicative level.

Regarding the second objective, the investigation of the duration and type of stroke, the results showed that these are not a significant moderator. Of all the studies included in the meta-analysis, 15 


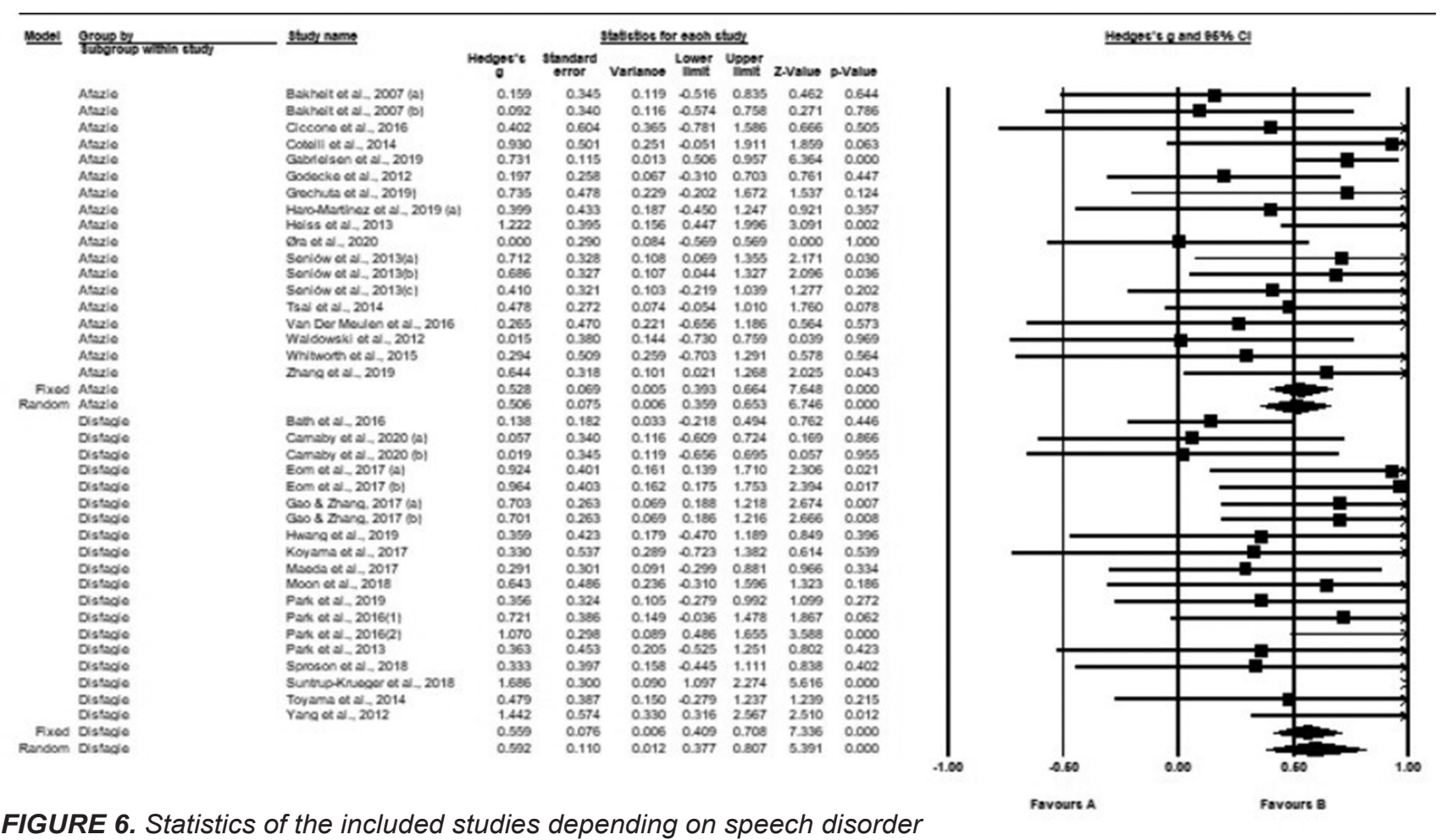

represent recovery in the acute type of stroke, 14 in chronic type, and for two of them no indicators of the type of stroke were identified. Therefore, according to the results, recovery is not conditioned by the starting time of therapy, and speech disorders can be improved even more than 3 months after stroke.

Sustainability over time is not conditioned by the time when the last evaluation of the results of the intervention was made [4]. Therefore, it can be stated that there is convincing evidence that the effects of the treatment are maintained over time.

\section{CONCLUSIONS}

The results of the present study support the fact that it is important that such a multidisciplinary intervention should be started, not only focusing on drug treatment but also on a psychological and psycho-educational approach, which could lead to a faster and more sustainable recovery from speech disorders. This meta-analysis also has a number of limitations. Following the selection of the studies, only 31 could be selected to meet the inclusion cri- teria. A higher number of studies is indicated for more relevant results. Another limitation is the intervention programs, which include a wide range of types of intervention, combinations of own methods and methodologies of application and duration, which makes it difficult to understand the exact and best functionality of an intervention. As a result, in future studies, some potentially important moderators may be considered, such as the duration of the intervention or the type of intervention applied to patients. The third limitation refers to the fact that other speech disorders, such as dysarthria, could not be included in the meta-analysis, as it is impossible to find a sufficient number of experimental and controlled studies for this disorder.

Concomitant cognitive deficits could increase the risk of recovery, therefore a multidisciplinary collaboration in the treatment of aphasia and dysphagia is required. Collaborative intervention between medical professionals and clinical psychologists could promote intervention procedures, adapted and combined, which are the subject to the improvement and recovery of speech disorders. 


\section{REFERENCES}

1. Eraifej J, Clark W, France B, Desando S, Moore D. Effectiveness of upper limb functional electrical stimulation after stroke for the improvement of activities of daily living and motor function: a systematic review and meta-analysis. Syst Rev. 2017 Feb 28;6(1):40.

2. Brady MC, Kelly H, Godwin J, Enderby P, Campbell P. Speech and language therapy for aphasia following stroke. Cochrane Database Syst Rev. 2016 Jun 1;2016(6):CD000425.

3. Duncan S, McAuley DF, Walshe M, McGaughey J, Anand R, Fallis $\mathrm{R}$, Blackwood $\mathrm{B}$. Interventions for oropharyngeal dysphagia in acute and critical care: a systematic review and meta-analysis. Intensive Care Med. 2020 Jul;46(7):1326-1338.

4. Van Der Meulen I, Van De Sandt-Koenderman MW, Heijenbrok MH, Visch-Brink E, Ribbers GM. Melodic Intonation Therapy in Chronic Aphasia: Evidence from a Pilot Randomized Controlled Trial. Front Hum Neurosci. 2016 Nov 1;10:533.

5. Bakheit AM, Shaw S, Barrett L, Wood J, Carrington S, Griffiths S, Searle K, Koutsi F. A prospective, randomized, parallel group, controlled study of the effect of intensity of speech and language therapy on early recovery from poststroke aphasia. Clin Rehabil. 2007 Oct;21(10):885-94.

6. Bath PM, Scutt P, Love J, Clavé P, Cohen D, Dziewas R, et al.; Swallowing Treatment Using Pharyngeal Electrical Stimulation (STEPS) Trial Investigators. Pharyngeal Electrical Stimulation for Treatment of Dysphagia in Subacute Stroke: A Randomized Controlled Trial. Stroke. 2016 Jun;47(6):1562-70.

7. Carnaby GD, LaGorio L, Silliman S, Crary M. Exercise-based swallowing intervention (McNeill Dysphagia Therapy) with adjunctive NMES to treat dysphagia post-stroke: A double-blind placebocontrolled trial. J Oral Rehabil. 2020 Apr;47(4):501-510.

8. Ciccone N, West D, Cream A, Cartwright J, Rai T, Granger A, Hankey GJ, Godecke E. Constraint-induced aphasia therapy (CIAT): a randomised controlled trial in very early stroke rehabilitation. Aphasiology. 2016;30(5):566-584.

9. Cotelli M, Manenti R, Petesi M, Brambilla M, Cosseddu M, Zanetti O, Miniussi C, Padovani A, Borroni B. Treatment of primary progressive aphasias by transcranial direct current stimulation combined with language training. J Alzheimers Dis. 2014; 39(4):799-808.

10. Eom MJ, Chang MY, Oh DH, Kim HD, Han NM, Park JS. Effects of resistance expiratory muscle strength training in elderly patients with dysphagic stroke. NeuroRehabilitation. 2017;41(4):747-752.

11. Hjelle EG, Bragstad LK, Kirkevold M, Zucknick M, Bronken BA, et al. Effect of a dialogue-based intervention on psychosocial well-being 6 months after stroke in Norway: A randomized controlled trial. J Rehabil Med. 2019 Sep 3;51(8):557-565.

12. Gao J, Zhang, HJ. Effects of chin tuck against resistance exercise versus Shaker exercise on dysphagia and psychological state after cerebral infarction. European Journal of Physical and Rehabilitation Medicine. 2017;53(3):7.

13. Godecke E, Hird K, Lalor EE, Rai T, Phillips MR. Very early poststroke aphasia therapy: a pilot randomized controlled efficacy trial. Int J Stroke. 2012 Dec;7(8):635-44.

14. Grechuta K, Ballester BR, Munne RE, Bernal TU, Hervás BM, Mohr $B$, et al. Augmented dyadic therapy boosts recovery of language function in patients with non-fluent aphasia: A randomised controlled trial. Stroke. 2019;50(5);1270-4.

15. Haro-Martínez AM, Lubrini G, Madero-Jarabo R, Díez-Tejedor E, Fuentes B. Melodic intonation therapy in post-stroke nonfluent aphasia: a randomized pilot trial. Clin Rehabil. 2019 Jan; 33(1):44-53.

16. Heiss WD, Hartmann A, Rubi-Fessen I, Anglade C, Kracht L, Kessler J, Weiduschat N, Rommel T, Thiel A. Noninvasive brain stimulation for treatment of right- and left-handed poststroke aphasics. Cerebrovasc Dis. 2013;36(5-6):363-72.

17. Hwang NK, Kim HH, Shim JM, Park JS. Tongue stretching exercises improve tongue motility and oromotor function in patients with dysphagia after stroke: A preliminary randomized controlled trial. Arch Oral Biol. 2019 Dec;108:104521.
18. Koyama Y, Sugimoto A, Hamano T, Kasahara T, Toyokura M, Masakado Y. Proposal for a Modified Jaw Opening Exercise for Dysphagia: A Randomized, Controlled Trial. Tokai J Exp Clin Med. 2017 Jul 20;42(2):71-78.

19. Maeda K, Koga T, Akagi J. Interferential current sensory stimulation, through the neck skin, improves airway defense and oral nutrition intake in patients with dysphagia: a double-blind randomized controlled trial. Clin Interv Aging. 2017 Nov 7;12:1879-1886.

20. Moon JH, Hahm SC, Won YS, Cho HY. The effects of tongue pressure strength and accuracy training on tongue pressure strength, swallowing function, and quality of life in subacute stroke patients with dysphagia: a preliminary randomized clinical trial. Int J Rehabil Res. 2018 Sep;41(3):204-210.

21. Øra HP, Kirmess M, Brady MC, Partee I, Hognestad RB, Johannessen BB, Thommessen B, Becker F. The effect of augmented speech-language therapy delivered by telerehabilitation on poststroke aphasia-a pilot randomized controlled trial. Clin Rehabil. 2020 Mar;34(3):369-381.

22. Park JS, Lee G, Jung YJ. Effects of game-based chin tuck against resistance exercise vs head-lift exercise in patients with dysphagia after stroke: An assessor-blind, randomized controlled trial. J Rehabil Med. 2019 Oct 29;51(10):749-754.

23. Park JS, Oh DH, Chang MY, Kim KM. Effects of expiratory muscle strength training on oropharyngeal dysphagia in subacute stroke patients: a randomised controlled trial. J Oral Rehabil. 2016 May;43(5):364-72.

24. Park JS, Oh DH, Hwang NK, Lee JH. Effects of neuromuscular electrical stimulation combined with effortful swallowing on post-stroke oropharyngeal dysphagia: a randomised controlled trial. J Oral Rehabil. 2016 Jun;43(6):426-34.

25. Park JW, Oh JC, Lee JW, Yeo JS, Ryu KH. The effect of $5 \mathrm{~Hz}$ high-frequency rTMS over contralesional pharyngeal motor cortex in post-stroke oropharyngeal dysphagia: a randomized controlled study. Neurogastroenterol Motil. 2013 Apr;25(4):324-e250.

26. Seniów J, Waldowski K, Leśniak M, Iwański S, Czepiel W, Członkowska A. Transcranial magnetic stimulation combined with speech and language training in early aphasia rehabilitation: a randomized double-blind controlled pilot study. Top Stroke Rehabil. 2013 May-Jun;20(3):250-61.

27. Sproson L, Pownall S, Enderby P, Freeman J. Combined electrical stimulation and exercise for swallow rehabilitation post-stroke: a pilot randomized control trial. Int J Lang Commun Disord. 2018 Mar;53(2):405-417

28. Suntrup-Krueger S, Ringmaier C, Muhle P, Wollbrink A, Kemmling A, Hanning U, Claus I, Warnecke T, Teismann I, Pantev C, Dziewas R. Randomized trial of transcranial direct current stimulation for poststroke dysphagia. Ann Neurol. 2018 Feb;83(2):328-340.

29. Tsai PY, Wang CP, Ko JS, Chung YM, Chang YW, Wang JX. The Persistent and Broadly Modulating Effect of Inhibitory rTMS in Nonfluent Aphasic Patients: A Sham-Controlled, Double-Blind Study. Neurorehabilitation and Neural Repair. 2014;28(8):779-787.

30. Waldowski K, Seniów J, Leśniak M, Iwański S, Członkowska A. Effect of Low-Frequency Repetitive Transcranial Magnetic Stimulation on Naming Abilities in Early-Stroke Aphasic Patients: A Prospective, Randomized, Double-Blind Sham-Controlled Study. The Scientific World Journal, 2012;1-8.

31. Whitworth A, Leitão S, Cartwright J, Webster J, et al. NARNIA: a new twist to an old tale. A pilot RCT to evaluate a multilevel approach to improving discourse in aphasia. Aphasiology. 2015;29(11):1345-1382.

32. Yang EJ, Baek SR, Shin J, Lim JY, Jang HJ, Kim YK, Paik NJ. Effects of transcranial direct current stimulation (tDCS) on post-stroke dysphagia. Restor Neurol Neurosci. 2012;30(4):303-11.

33. Zhang H, Li H, Li R, Xu G, Li Z. Therapeutic effect of gradual attention training on language function in patients with post-stroke aphasia: a pilot study. Clin Rehabil. 2019 Nov;33(11):1767-1774. 